\title{
Factors associated with opioid dispensation for patients with COPD and lung cancer in the last year of life:A retrospective analysis
}

This article was published in the following Dove Press journal:

International Journal of COPD

9 April 2010

Number of times this article has been viewed

\author{
Donna Goodridge' \\ Josh Lawson ${ }^{2}$ \\ Graeme Rocker ${ }^{3}$ \\ Darcy Marciniuk ${ }^{4}$ \\ Donna Rennie ${ }^{1,2}$ \\ 'College of Nursing, ${ }^{2}$ Canadian Centre \\ for Health and Safety in Agriculture, \\ University of Saskatchewan, \\ Saskatoon, Saskatchewan, Canada; \\ ${ }^{3}$ Faculty of Medicine, Dalhousie \\ University, Halifax, Nova Scotia, \\ Canada; ${ }^{4}$ College of Medicine. \\ University of Saskatchewan, \\ Saskatoon, Saskatchewan, Canada
}

Correspondence: Donna Goodridge College of Nursing, University of Saskatchewan, 107 Wiggins Rd, Saskatoon, Saskatchewan, S7N 5E5 Tel | 306966 | 478

Fax I 3069666703

Email donna.goodridge@usask.ca
Background: For patients in late stages of chronic obstructive pulmonary disease (COPD), dyspnea is often refractory to conventional treatment. We know little about the use of opioids in ameliorating dyspnea in this population. In this study we explored factors associated with opioid dispensation within the last year of life and differences in opioid dispensation for persons with lung cancer or COPD.

Methods: In this retrospective cohort study we used administrative health data gained from 1,035 residents of Saskatchewan, Canada to examine patterns of community opioid dispensation in the last year of life. Factors associated with opioid use were determined using multiple logistic regression.

Results: When compared with those with lung cancer, fewer patients with COPD were given opioids within the last week of life; the last month of life, and the last 3 months of life. After adjusting for relevant predictors, patients with lung cancer were more than twice as likely as those with COPD to fill prescriptions for the following: morphine (odds ratio [OR] 2.36, 95\% confidence interval [CI]: 1.52-3.67); hydromorphone (OR 2.69, 95\% CI: 1.53-4.72); transdermal fentanyl (OR 2.25, 95\% CI: 1.28-3.98); or any of these opioids (OR 2.61, 95\% CI: $1.80-3.80)$.

Conclusion: These opioids are dispensed only for a small proportion of patients with COPD at the end of their lives. Future researchers could explore the efficacy and safety of opioid use for patients with advanced COPD, and whether their limited use is justified.

Keywords: COPD, lung cancer, dyspnea, opioid dispensation, palliative care

\section{Background}

Concerns about suboptimal care and symptom management in persons with advanced chronic obstructive pulmonary disease $(\mathrm{COPD})^{1-8}$ warrant the reexamination of interventions for this population. COPD is the fourth most common cause of death in Canada, ${ }^{9}$ with escalating prevalence, morbidity, and attributable mortality rates. ${ }^{10}$

Symptom burden is as high or higher at the end of life for persons with COPD compared to those with lung cancer. ${ }^{1-3,5-8}$ Pain due to local invasion or metastases is a well-recognized terminal symptom in lung cancer. ${ }^{11-13}$ While there have been few investigations of pain in persons with advanced COPD, in a recent study one third of patients with advanced COPD reported significant pain. ${ }^{14}$

Between $32 \%$ and $79 \% \%^{2,11-13}$ of persons with lung cancer and $56 \%-95 \% \%^{2,12,14-16}$ of those with COPD experience dyspnea in the last days or weeks of life. Although unrelieved dyspnea is one of the most common and distressing physical symptoms at the end of life $\mathrm{e}^{3,17-19}$ and our understanding of refractory dyspnea is increasing, ${ }^{20,21}$ patients 
with advanced COPD are not provided with therapeutic approaches more commonly used in the setting of malignant disease.

Opioids are frequently used to control symptoms, including pain and dyspnea, in patients with advanced cancer, ${ }^{19}$ but investigations into their use in other life-threatening diseases have been limited. Entrenched fears among physicians - and perhaps among patients - may impose barriers to more widespread use. ${ }^{22}$ It is often mistakenly assumed that the use of opioids will hasten death through respiratory depression, ${ }^{23-25}$ although there is no evidence to support this among patients where opioids are titrated carefully to effect. ${ }^{26}$ According to the American Pain Society, ${ }^{26}$ withholding appropriate opioids based on respiratory concerns is typically unwarranted and can lead to unnecessary suffering.

For patients in late stages of COPD, dyspnea is often refractory to conventional treatment. While opioids may be of benefit in ameliorating dyspnea, we know little about their use in those dying from COPD. The purpose in our study was to explore predictors of opioid use in the last year of life and describe any differences in the opioid dispensation for those who died from lung cancer as compared to those who died from COPD.

\section{Methods}

\section{Study population and design}

A retrospective study was conducted within the province of Saskatchewan, Canada (population 1,020,000) using administrative data provided by the Saskatchewan Ministry of Health (Saskatchewan Health), ${ }^{27}$ which have been previously used to conduct large epidemiological studies of respiratory health. ${ }^{28-30}$ Individuals who had either lung cancer (ICD-10 code C34.x) as the underlying cause of death (UCOD) or COPD (ICD-10 code J44.x) or a multiple cause of death (MCOD) and had died in 2004 were selected. The index date was the date of death. This study was approved by the University of Saskatchewan Biomedical Research Ethics Board.

\section{Saskatchewan Health administrative data}

Universal health care coverage is provided by Saskatchewan Health for the majority of the population (99\%) in the province, with the exception of persons covered by the federal government. Registered Indians are not covered under the provincial drug plan because they receive prescription benefits from the federal government and this population has therefore been excluded from the present study. Each person insured by Saskatchewan Health is assigned a unique identifier that can be used to link the various databases. Prior to receiving the data from Saskatchewan Health, the unique identifier was removed and the dataset deidentified. The administrative data used in this study included: participant file, hospital discharges, home care services, institutional supportive care services, the vital statistics information file, and the outpatient prescription drug services.

The compiled participant file contained the following demographic information: sex, year of birth, marital status, category of residence (ie, rural, small urban, or urban), and study entry and index dates. The hospitalization services file included dates of admission and discharge, diagnoses of interest and diagnosis type, and procedures of interest undertaken during hospitalization. Dates of admission and discharge for home care, months eligible for services during the last year of life, and amount of time spent on specific types of home care duties are situated in the home care file. The institutional supportive care file includes dates of admission and discharge, type of program, purpose of temporary care, level of care, and type of facility. Data in the prescription drug file (which includes drug category, dispensing date, and for drugs of interest: strength, form, and quantity dispensed) reflect all prescriptions filled outside of hospitals through the Saskatchewan Prescription Drug Plan.

\section{Opioid dispensing}

Determination of opioid dispensing was based on the outpatient prescription drug database. Medications considered included the oral and non-oral forms of selected strong opioids: morphine, hydromorphone, and transdermal fentanyl. Dispensing of a prescription was considered within specified time frames: 7 days, 30 days, 3 months, 6 months, and 12 months prior to death.

\section{Operational definitions of predictor variables}

Comorbid conditions were classified by the number of conditions present $(>1$ or $\leq 1)$ based on the presence or absence of disease conditions included in the underlying cause of death (UCOD) or multiple causes of death (MCOD). Place of death was considered as home, hospital, or institutional care facility and was determined by comparing date of death with concurrent admission to hospital or long-term care. Category of residence was classified as urban (ie, population size $>100,000$ ), small urban (ie, 10,000-99,000), or rural/ remote (ie, $<10,000$ ). The number of care transitions (ie, tran- 
sitions between hospital, home, or long term care facilities) were derived from using dates of admission and discharge and classified into categories of $0-4$ and $\geq 5$ transitions.

\section{Statistical analysis}

Statistical analyses were carried out using SPSS version 17.0. Level of significance $(\sigma)$ was set at 0.05 . The variable of primary interest was the two-level disease group variable indicating lung cancer or COPD. Comparisons between the two groups were completed using $t$-tests and chi-square tests of proportion where appropriate. When the assumptions for these tests were not met, Mann-Whitney and Fisher's Exact tests were implemented.

Associations between the predictor variables, including disease group and opioid dispensation outcomes, were assessed using multiple logistic regression to adjust for potential confounding. The strength of association was measured by the odds ratio (OR) and 95\% confidence intervals (CI). Interactions between disease group and the other predictor variables, as well as clinically relevant interactions were assessed. When interaction was significant, the odds ratios were adjusted for the interaction.

\section{Results}

Saskatchewan health beneficiaries eligible for prescription drug benefits were selected for the study if they died during 2004 and the vital statistics database reported either lung cancer $(n=433)$ as the underlying cause of death or COPD $(\mathrm{n}=602)$ as their underlying (UCOD) or multiple (MCOD) cause of death. Compared to those with COPD, decedents from lung cancer in this sample were younger ( 81.6 versus 71.6 years, $P<0.005$ ), had fewer comorbid conditions (2.18 versus $1.44, P<0.005$ ), and were less likely to be widowed (24.4\% versus $13.2 \%, P<0.05)$. A lower proportion of patients with COPD (versus lung cancer) died in hospital than persons with lung cancer $(49.3 \%$ versus $68.4, P<0.05)$, based on a discharge date from hospital matching the date of death, and a higher proportion of persons with COPD died in long term care institutions ( $34.9 \%$ versus $17.8 \%, P<0.05$ ), based on a discharge date from hospital matching the date of death. Significantly more persons who died from lung cancer (37.4\%) received home palliative care services than those who died from COPD $(2.8 \%, P<0.005)$. The groups were comparable in terms of representation by sex, urban/rural residence, and proportion of home deaths.

As seen in Table 1, within the last three months of life, dispensation of any forms of morphine, hydromorphone, or fentanyl were filled at least once for almost half $(47.6 \%)$ of all
Table I Community opioid prescriptions by time period prior to death among participants with COPD or lung cancer (\%)

\begin{tabular}{|c|c|c|}
\hline $\begin{array}{l}\text { Opioid prescriptions in time } \\
\text { period prior to death }\end{array}$ & $\begin{array}{l}\text { Lung cancer } \\
n=433\end{array}$ & $\begin{array}{l}\text { COPD } \\
n=602\end{array}$ \\
\hline \multicolumn{3}{|l|}{ Morphine, oral (yes/no) } \\
\hline Within 7 days of death & $7.9^{\dagger}$ & 4.3 \\
\hline Within 30 days of death & $22.6^{\dagger}$ & 6.8 \\
\hline At any point in the last 3 months & $30.9 *$ & 9.0 \\
\hline Within 6 months prior to death & 3.9 & 3.3 \\
\hline Within 12 months prior to death & 1.2 & 1.7 \\
\hline \multicolumn{3}{|l|}{ Morphine, nonoral (yes/no) } \\
\hline Last 7 days of life & 3.7 & 2.5 \\
\hline Last 3 months of life & $2.5^{\dagger}$ & 0.7 \\
\hline \multicolumn{3}{|l|}{ Hydromorphone, oral (yes/no) } \\
\hline Within 7 days of death & $5.5 *$ & 1.3 \\
\hline Within 30 days of death & $11.7^{\dagger}$ & 3.0 \\
\hline At any point in the last 3 months & $20.1 *$ & 4.3 \\
\hline Within 6 months prior to death & 2.8 & 1.3 \\
\hline Within 12 months prior to death & 1.2 & 1.0 \\
\hline \multicolumn{3}{|c|}{ Hydromorphone, nonoral (yes/no) } \\
\hline Last 7 days of life & $2.1^{\dagger}$ & 0.5 \\
\hline Last 3 months of life & 0 & 0.2 \\
\hline \multicolumn{3}{|l|}{ Transdermal Fentanyl (yes/no) } \\
\hline Within 7 days of death & $5.5 *$ & 2.0 \\
\hline Within 30 days of death & $14.5^{\dagger}$ & 4.2 \\
\hline At any point in the last 3 months & $17.3 *$ & 5.5 \\
\hline Within 6 months prior to death & 2.5 & 2.0 \\
\hline Within 12 months prior to death & 0.7 & 1.3 \\
\hline
\end{tabular}

Notes: $* p<0.005$ between the lung cancer and COPD groups using the chi-square tests for proportions. ${ }^{t} P<0.05$ between the lung cancer group and the lung cancer and COPD group using the chi-square tests for proportions.

Abbreviation: COPD, chronic obstructive pulmonary disease.

patients with lung cancer, but only for $15.6 \%$ of patients with COPD $(P<0.001)$. Compared to those with COPD, consistently higher proportions of patients with lung cancer filled prescriptions within the last seven days, last month, or last three months for oral morphine, oral hydromorphone, and/or transdermal fentanyl (Table 1). In the three months prior to death, morphine prescriptions were filled more frequently for both persons with lung cancer (30.9\%) and those with COPD $(9.0 \%)$ than were prescriptions for hydromorphone ( $20.1 \%$ versus $4.3 \%$ respectively) or fentanyl ( $14.5 \%$ versus $4.2 \%$ respectively). At 6 or 12 months before death, opioid dispensing was uncommon in both groups.

Because these data did not reflect opioids used while in hospital, and because the groups differed in terms of proportions of deaths occurring in hospital, further analysis was conducted using the subsets of all persons who died in hospital, at home, and those who died in a long-term care facility. 
As seen in Table 2, higher proportions of patients with lung cancer than those with COPD were dispensed opioids within 30 days and three months prior to death, regardless of place of death. The exception to these findings occurs with morphine prescriptions in the last seven days of life, where there is no difference between the disease groups. When compared with the overall sample, higher proportions of persons who died at home or in a long-term care setting had community opioid prescriptions dispensed in their last seven days of life (Table 2).

After adjusting for other predictors (Table 3), patients with lung cancer were at least twice as likely as those with COPD to be dispensed: any of the three selected opioids (OR 2.61, 95\% CI: 1.80-3.80): oral morphine (OR 2.36, 95\% CI: 1.52-3.67); oral hydromorphone (OR 2.69, 95\% CI: 1.53-4.72); or transdermal fentanyl (OR 2.25, 95\% CI: 1.28-3.98). In addition to receiving home palliative care, having $\geq 5$ care transitions and living in an area with a population of 10,000-99,000 consistently increased the likelihood of having opioid prescriptions filled, regardless of type of opioid (Table 3).

Associations between opioid use and other predictors were more variable (Table 3). Being female was associated with increased likelihood of having prescriptions filled for any opioid or transdermal fentanyl but not for morphine or hydromorphone. Persons who died in a long term care institution were more likely than those who died in hospital to have had prescriptions filled in the last three months of life for any opioid, oral morphine, or fentanyl. Persons who died at home were more likely than those who died in hospital to have prescriptions filled for any opioid but not for the oral forms of morphine, hydromorphone, or fentanyl. Advanced age (80-85, or greater than 85 years) was associated with a significantly decreased likelihood of having prescriptions filled for any opioid oral morphine or oral hydromorphone but not for fentanyl. Finally, having two or more comorbid conditions was associated with a decreased likelihood of having an oral morphine prescription filled.

A stratified analysis was completed to examine associations between disease status and opioid use in the last three months by the area of residence. The results are presented in Table 4 where it can be seen that for each opioid dispensation outcome, there is an increased likelihood of dispensing a prescription, regardless of the opioid type, for those with lung cancer compared to those with COPD when living in a rural area. Among the large urban and small urban areas, the associations were not statistically significant, although there were associations of borderline statistical significance

Table 2 Community opioid prescriptions prior to death among participants with COPD or lung cancer by place of death (\%)

\begin{tabular}{|c|c|c|c|c|c|c|}
\hline \multirow[t]{2}{*}{$\begin{array}{l}\text { Opioid prescription in } \\
\text { time period prior to death }\end{array}$} & \multicolumn{2}{|l|}{ Hospital death } & \multicolumn{2}{|l|}{ Home death } & \multicolumn{2}{|c|}{$\begin{array}{l}\text { Long-term care institution } \\
\text { death }\end{array}$} \\
\hline & $\begin{array}{l}\text { Lung cancer } \\
\mathrm{n}=296\end{array}$ & $\begin{array}{l}\text { COPD } \\
n=297\end{array}$ & $\begin{array}{l}\text { Lung cancer } \\
n=60\end{array}$ & $\begin{array}{l}\text { COPD } \\
n=95\end{array}$ & $\begin{array}{l}\text { Lung cancer } \\
\mathbf{n = 7 7}\end{array}$ & $\begin{array}{l}\text { COPD } \\
n=210\end{array}$ \\
\hline \multicolumn{7}{|l|}{ Morphine, oral (yes/no) } \\
\hline Within 7 days of death & 2.4 & 1.4 & $22.3^{\dagger}$ & 17.6 & $16.9 *$ & 8.6 \\
\hline Within 30 days of death & $18.9^{\dagger}$ & 4.4 & $38.3^{\dagger}$ & 3.2 & $24.7^{*}$ & 11.9 \\
\hline At any point in the last 3 months & $27.4^{*}$ & 6.7 & $43.3^{*}$ & 33.3 & $35.1^{\dagger}$ & 13.8 \\
\hline Within 6 months prior to death & 4.4 & 2.4 & 1.0 & 4.2 & 3.9 & 4.3 \\
\hline Within 12 months prior to death & 1.4 & 1.0 & 0 & 3.2 & 1.3 & 1.9 \\
\hline \multicolumn{7}{|l|}{ Hydromorphone, oral (yes/no) } \\
\hline Within 7 days of death & $4.7^{*}$ & 1.0 & $8.3^{\dagger}$ & I.I & $6.5^{*}$ & 0.5 \\
\hline Within 30 days of death & $14.2^{\dagger}$ & 2.4 & $20.0 *$ & 4.2 & $18.2^{\dagger}$ & 3.3 \\
\hline At any point in the last 3 months & $18.9^{\dagger}$ & 4.4 & $6.7^{*}$ & 3.2 & $22.1^{\dagger}$ & 3.8 \\
\hline Within 6 months prior to death & 2.7 & 1.0 & 5.0 & I.I & 1.3 & 1.9 \\
\hline Within 12 month prior to death & 0.3 & 0.7 & 1.7 & 0 & 3.9 & 1.9 \\
\hline \multicolumn{7}{|l|}{ Transdermal fentanyl (yes/no) } \\
\hline Within 7 days of death & $3.4^{*}$ & 1.0 & $8.3^{*}$ & I.I & $11.7^{*}$ & 3.8 \\
\hline Within 30 days of death & $11 . I^{\dagger}$ & 1.0 & $20.0 *$ & 3.2 & $23.4^{\dagger}$ & 9.0 \\
\hline At any point in the last 3 months & $13.9^{\dagger}$ & 2.7 & 5.0 & I.I & $26.0 *$ & 10.5 \\
\hline Within 6 month prior to death & 2.0 & 0.3 & 1.7 & 1.1 & 5.2 & 4.8 \\
\hline Within 12 month prior to death & 0 & 0 & 0 & 0 & 3.9 & 3.8 \\
\hline
\end{tabular}

Notes: $* P<0.05$ between the lung cancer and COPD groups using the chi-square tests for proportions. ${ }^{\dagger} P<0.005$ between the lung cancer group and the lung cancer and COPD group using the chi-square tests for proportions.

Abbreviation: COPD, chronic obstructive pulmonary disease. 
Table 3 Multivariate* analysis examining associations between disease category, demographic characteristics, comorbidity, place of death, home palliative care, and care transitions with opioid prescriptions $(n=1035)$

$\begin{array}{llll}\text { Any opioid in last } & \text { Morphine (oral) in last } & \text { Hydromorphone } & \text { Fentanyl transdermal } \\ 3 \text { months OR }(95 \% \mathrm{Cl}) & 3 \text { months OR }(95 \% \mathrm{Cl}) & \begin{array}{l}\text { (oral) in last } 3 \text { months } \\ \text { OR }(95 \% \mathrm{Cl})\end{array} & \begin{array}{l}\text { in last } 3 \text { months OR } \\ (95 \% \mathrm{Cl})\end{array}\end{array}$

\begin{tabular}{|c|c|c|c|c|}
\hline \multicolumn{5}{|l|}{ Disease status } \\
\hline COPD & 1.00 & 1.00 & 1.00 & 1.00 \\
\hline Lung cancer & $2.6 \mathrm{I}(1.80-3.80)^{\dagger \dagger}$ & $2.36(1.52-3.67)^{\dagger \dagger}$ & $2.69(1.53-4.72)^{\dagger \dagger}$ & $2.25(1.28-3.98)^{\dagger \dagger}$ \\
\hline \multicolumn{5}{|l|}{ Age group } \\
\hline$\leq 70$ years & 1.00 & 1.00 & 1.00 & 1.00 \\
\hline $7 I-79$ years & $0.68(0.46-1.02)$ & $0.70(0.46-1.09)$ & $0.60(0.37-0.99)^{\dagger}$ & $0.67(0.39-1.16)$ \\
\hline $80-85$ years & $0.30(0.18-0.49)^{\dagger \dagger}$ & $0.38(0.2 \mathrm{I}-0.67)^{\dagger+}$ & $0.47(0.24-0.90)^{\dagger}$ & $0.53(0.27-1.07)$ \\
\hline$>85$ years & $0.37(0.22-0.62)^{\dagger \dagger}$ & $0.52(0.29-0.92)^{\dagger}$ & $0.21(0.09-0.52)^{\dagger \dagger}$ & $0.56(0.27-1.15)$ \\
\hline \multicolumn{5}{|l|}{ Sex } \\
\hline Male & 1.00 & 1.00 & 1.00 & 1.00 \\
\hline Female & $1.44(1.06-1.98)^{\dagger}$ & I.I4 (.82-I.63) & $1.01(0.66-1.55)$ & $1.89(1.22-2.90)^{\dagger \dagger}$ \\
\hline \multicolumn{5}{|l|}{ Area of residence } \\
\hline Urban $>100,000$ & 1.00 & 1.00 & 1.00 & 1.00 \\
\hline Small urban 10,000-99,999 & $1.75(1.14-2.69)^{\dagger}$ & $1.93(1.21-3.06)^{t \dagger}$ & $0.87(0.48-1.59)$ & $2.16(1.05-4.31)^{\dagger}$ \\
\hline Rural/remote $<10,000$ & $1.10(0.76-1.57)$ & $1.06(0.70-1.59)$ & $0.98(0.60-1.58)$ & $1.25(0.75-2.09)$ \\
\hline \multicolumn{5}{|l|}{ Comorbidity } \\
\hline $0-I$ condition & 1.00 & 1.00 & 1.00 & 1.00 \\
\hline 2 or more conditions & $0.76(0.54-1.06)$ & $0.57(0.39-0.83)^{\dagger \dagger}$ & $1.24(0.78-1.97)$ & $0.99(0.62-1.58)$ \\
\hline \multicolumn{5}{|l|}{ Place of death } \\
\hline Hospital & 1.00 & 1.00 & 1.00 & 1.00 \\
\hline Institution & $3.37(2.21-4.98)^{\dagger \dagger}$ & $2.38(1.52-3.69)^{\dagger \dagger}$ & I.48 (0.85-2.85) & $3.34(1.05-4.31)^{\dagger}$ \\
\hline Home & $2.09(1.31-3.33)^{\dagger \dagger}$ & $1.48(0.84-2.35)$ & $1.28(0.70-2.36)$ & $1.57(.75-2.09)$ \\
\hline \multicolumn{5}{|l|}{$\begin{array}{l}\text { Receiving home } \\
\text { palliative care }\end{array}$} \\
\hline No home palliative care & 1.00 & 1.00 & 1.00 & 1.00 \\
\hline Home palliative care & $3.72(2.45-5.65)^{\dagger \dagger}$ & $2.64(1.72-4.06)^{\dagger+}$ & $2.79(1.70-4.59)^{\dagger \dagger}$ & $3.14(1.85-5.36)^{\dagger \dagger}$ \\
\hline \multicolumn{5}{|l|}{$\begin{array}{l}\text { Care transitions in last } \\
\text { year of life }\end{array}$} \\
\hline $0-4$ care transitions & 1.00 & 1.00 & 1.00 & 1.00 \\
\hline$\geq 5$ transitions & $1.95(1.41-2.68)^{\dagger \dagger}$ & $1.48(1.03-2.11)^{\dagger}$ & $2.16(1.39-3.39)^{\dagger \dagger}$ & $1.72(1.10-2.69)^{\dagger}$ \\
\hline
\end{tabular}

Notes: *Adjusted for all the variables in the table. ${ }^{\dagger} P<0.05$; ${ }^{\dagger} P<0.005$.

Abbreviations: $\mathrm{OR}$, odds ratio; $\mathrm{Cl}$, confidence interval.

$(P<0.10)$ with increased likelihood of filling opioid prescriptions among those with lung cancer for fills of morphine and hydromorphone when living in the large or small urban, and the small areas, respectively.

\section{Discussion}

Our findings demonstrate that dispensation of any of these three opioids is relatively uncommon in the last seven and last 30 days of life for persons with COPD who died at home $(17.6 \%, 3.2 \%)$ or in long-term care institutions $(8.6 \%$, $11.9 \%)$. Given that estimates of severe dyspnea among persons with COPD range as high as $95 \%,{ }^{15}$ that dyspnea has been cited as the most distressing symptom at the end of life for persons with COPD, ${ }^{15,16}$ and that the effectiveness of conventional therapies in managing dyspnea, such as long-term oxygen therapy, remain questionable, ${ }^{31}$ the use of strong opioids in this population was very low. In the last three months of life, however, these three opioids had been prescribed at some point for one third of those with COPD who died at home, suggesting that these three opioids are in fact being considered as an option for some individuals with end-stage COPD. The drop in the number of opioid prescriptions filled at seven days compared with 30 days prior to death might reflect a change in route to subcutaneous administra- 
Table 4 Multivariate analysis examining the association between disease category and opioid prescriptions by area of residence

\begin{tabular}{|c|c|c|c|c|}
\hline & $\begin{array}{l}\text { Any opioid in last } 3 \\
\text { months OR }(95 \% \mathrm{Cl})\end{array}$ & $\begin{array}{l}\text { Morphine (oral) in last } \\
3 \text { months OR }(95 \% \mathrm{Cl})\end{array}$ & $\begin{array}{l}\text { Hydromorphone (oral) } \\
\text { in last } 3 \text { months OR }(95 \% \mathrm{Cl})\end{array}$ & $\begin{array}{l}\text { Fentanyl transdermal in } \\
\text { last } 3 \text { months OR }(95 \% \mathrm{Cl})\end{array}$ \\
\hline \multicolumn{5}{|c|}{ Urban $>100,000$} \\
\hline COPD & 1.00 & 1.00 & 1.00 & 1.00 \\
\hline Lung cancer & $1.64(0.84-3.17)$ & $2.11(0.95-4.71)^{\dagger}$ & $1.23(0.47-3.24)$ & $1.45(0.5 \mathrm{I}-4.16)$ \\
\hline \multicolumn{5}{|l|}{$10,000-29,999$} \\
\hline COPD & 1.00 & 1.00 & 1.00 & 1.00 \\
\hline Lung cancer & $1.92(0.82-4.48)$ & $2.25(0.92-5.50)^{\dagger}$ & $3.70(0.85-16.21)^{\dagger}$ & $2.36(0.79-7.09)$ \\
\hline \multicolumn{5}{|c|}{ Rural/remote $<10,000$} \\
\hline COPD & 1.00 & 1.00 & 1.00 & 1.00 \\
\hline Lung cancer & $4.58(2.59-8.09)^{*}$ & $2.82(1.42-5.60)^{*}$ & $4.95(2.10-11.70)^{*}$ & $3.96(1.51-10.39)^{*}$ \\
\hline
\end{tabular}

Notes: Adjusted for age group, sex, comorbidity, place of death, receiving home palliative care, and number of care transitions. $* P<0.01$; ${ }^{\dagger}<0.10$.

Abbreviations: $\mathrm{Cl}$, confidence interval; $\mathrm{COPD}$, chronic obstructive pulmonary disease; OR, odds ratio.

tion. Terminal dysphagia may have precluded the use of oral morphine, while transdermal formulations cannot be titrated to optimize optimal symptom management.

Our findings also demonstrate that individuals who died from lung cancer were twice as likely as those with COPD to have had community prescriptions filled for three selected opioids in the last seven days, last month, and last three months of life. Because the administrative data do not provide a rationale for opioid prescription, however, we can only speculate about that the primary motivation for opioid prescriptions for persons who died with lung cancer may have been pain rather than dyspnea.

We also found that several factors associated with the category other than disease were related to an increased likelihood of any of the three opioids being dispensed. Only $2.8 \%$ of persons with COPD received palliative home care. Persons who received palliative home care, however, had a two- or threefold higher likelihood of any of the three opioids dispensed at the end of life, potentially reflecting the increased focus of palliative programs on symptom management. Persons who died from COPD were significantly older than those who died from lung cancer in this sample and older age was associated with a decreased likelihood of being prescribed morphine or hydromorphone.

This study was limited by the constraints inherent in using an administrative database, such as potential inaccuracy of coding and lack of information relating to areas of interest, such as reasons for opioid prescription and disease severity. The symptoms experienced by individuals with COPD compared with those with lung cancer at the end of life may have differed in both nature and severity, necessitating different management strategies. The administrative data represent one Canadian province only and may have limited generalizability because of regional variation in practice, but the data do represent an entire population. The data analyzed in this report do not provide assessment of quality of life or appropriateness or adequacy of care to those who died from either lung cancer or COPD.

The strengths of this study included access to 12 months of comprehensive health care data for an entire cohort of decedents in a geographically large and diverse province in 2004. The dataset was robust, with few missing data, and captured care that occurred across multiple settings, thus reflecting the full spectrum of treatments provided.

\section{Conclusions}

Morphine, hydromorphone, and transdermal fentanyl are prescribed for only a small proportion of patients with COPD at the end of life. Given the questionable effectiveness of conventional therapies including long-term oxygen therapy, ${ }^{31}$ the relatively low use of the three opioids among dying patients was surprising.

The efficacy and safety of opioids for treatment of dyspnea in patients living and dying with advanced COPD needs to be explored. The low utilization of opioids in this population is not consistent with the guidelines recommendations of expert opinions. ${ }^{9}$ Robust evidence regarding appropriate symptom palliation measures needs to be developed for the growing population of individuals who will die from COPD in the coming years.

\section{Acknowledgments}

We gratefully acknowledge the funding provided for this study by the Saskatchewan Health Research Foundation and the assistance provided by Mary Rose Stang, HEO, Saskatchewan Health. The author DG holds a Canadian Institutes of Health Research/Regional Partnerships Program New Investigator salary award. Authors DG, JL, DM, and 
DR contributed to the conceptualization, design, and initial analysis of data. Authors DG, JL, and GR were responsible for the analysis and preparation of this paper, which was reviewed by DM and DR.

Work was conducted at the University of Saskatchewan.

This study is based in part on deidentified data provided by the Saskatchewan Ministry of Health. The interpretation and conclusions contained herein do not necessarily represent those of the Government of Saskatchewan or the Saskatchewan Ministry of Health.

\section{Disclosures}

The authors report no conflicts of interest in this work.

\section{References}

1. Gore JM, Brophy CJ, Greenstone MA. How well do we care for patients with end stage chronic obstructive pulmonary disease (COPD)? A comparison of palliative care and quality of life in COPD and lung cancer. Thorax. 2000;55:1000-1006.

2. Claesens MT, Lynn J, Zhensao Z, et al. Dying with lung cancer or chronic obstructive pulmonary disease: Insights from SUPPORT. J Am Ger Soc. 2000;48:S146-S153.

3. Edmonds P, Karlsen S, Kahn S, et al. A comparison of the palliative care needs of patients dying from chronic respiratory diseases and lung cancer. Pall Med. 2001;15:287-295.

4. Skilbeck J, Mott L, Page H, et al. Palliative care in chronic obstructive airways disease: a needs assessment. Pall Med. 1998;12:245-254.

5. Tranmer JE, Heyland D, Dudgeon D, et al. Measuring the symptom experience of seriously ill cancer and non-cancer patients near the end of life with the Memorial Symptom Assessment Scale. J Pain Symp Man. 2003;25:420-429.

6. Fan VS, Curtis RJ, Tu SP, et al. Using quality of life to predict hospitalization and mortality in patients with obstructive lung disease. Chest 2002;122:429-436.

7. McKinley RK, Stokes T, Exley C, Field D. Care of people dying with malignant and cardiorespiratory disease in general practice. $\mathrm{Br} \mathrm{J} \mathrm{Gen}$ Prac. 2004;54:909-913.

8. Au DH, Udris EM, Fihn SD, et al. Differences in health care utilization at the end of life among patients with Chronic Obstructive Pulmonary Disease and patients with lung cancer. Arch Intern Med. 2006;166: 326-331.

9. Canadian Thoracic Society state of the art compendium: Canadian Thoracic Society recommendations for the management of chronic obstructive pulmonary disease. Can Resp J. 2004;11 Suppl B:3B-59B.

10. Hurd $\mathrm{S}$. The impact of COPD on lung health worldwide: epidemiology and incidence. Chest. 2000;117:1S-4S.

11. Potter J, Higginson I. Pain experienced by lung cancer patients: a review of the prevalence, causes and pathophysiology. Lung Ca. 2004;43: $247-257$.
12. Skaug K, Eide GE, Gulsvik A. Prevalence and predictors of symptoms in the terminal stage of lung cancer. Chest. 2007;131:389-394.

13. Bruera E, Schmitz B, Pither J, et al. The frequency and correlates of dyspnea in patients with advanced cancer. J Pain Symptom Manage. 2000;19:357-362.

14. Blinderman CD, Homel P, Billings A, et al. Symptom distress and quality of life in patients with advanced chronic obstructive pulmonary disease. J Pain Symp Manag. 2009;38(1):115-123.

15. Lynn J, Ely EW, Zhenshao Z, et al. Living and dying with chronic obstructive pulmonary disease. J Am Geriatr Soc. 2000;48: S91-S100.

16. Skilbeck J, Mott L, Page H, Smith D, Hjelmeland-Ahmedzai S, Clark D. Palliative care in chronic obstructive airways disease: a needs assessment. Palliat Med. 1998;12:245-254.

17. ZuWallack RL, Haggerty MC, Jones P. Clinically meaningful outcomes in patients with chronic obstructive pulmonary disease. $\mathrm{Am} \mathrm{J} \mathrm{Med}$. 2004;117:49S-59S.

18. Barnett M. Chronic obstructive pulmonary disease: a phenomenological study of patients' experiences. J Clin Nurs. 2005;14:805-812.

19. Jennings AL, Davies AN, Higgins JP, Gibbs JS, Broadley KE. A systematic review of the use of opioids in the management of dyspnoea. Thorax. 2002;57:939-944.

20. Currow DC, Agar M, Sanderson C, Abernethy AP. Populations who die without specialist palliative care: does lower uptake equate with unmet need? Palliat Med. 2008;22:43-50.

21. Currow DC, Ward AM, Clark K, Burns CM, Abernethy AP. Caregivers for people with end-stage lung disease: characteristics and unmet needs in the whole population. Int J Chron Obstruct Pulmon Dis. 2008;3:753-762.

22. Rocker GM, Sinuff T, Horton R, Hernandez P. Advanced chronic obstructive pulmonary disease: innovative approaches to palliation. $J$ Palliat Med. 2007;10:783-797.

23. Sykes N, Thorns A. Opioid use in the last week of life and implications for end of life decision-making. Lancet. 2000;356:398-399.

24. Sykes N, Thorns A. The use of opioids and sedatives at the end of life Lancet Oncology. 2003;4:312-318.

25. Billings JA, Block SD. Slow euthanasia. J Palliat Care. 1996;12:21-30.

26. Smith LH. Opioid safety: is your patient at risk for respiratory depression? Clin J Oncol Nurs. 2007;11:293-296.

27. Downey W, Stang MR, Beck P, Osei W, Nichol J. Health services databases in Saskatchewan. In: BL Strom, ( Ed.), Pharmacoepidemiology (4th ed.). Chichester: John Wiley and Sons, Ltd; 2005:295-310.

28. Senthilselvan A, Lawson JA, Rennie DC, et al. Stabilization of an increasing trend in physician-diagnosed asthma prevalence in Saskatchewan, 1991-1998. Chest. 2003;124:438-448.

29. Suissa S, Ernst P, Benayoun S, et al. Low-dose inhaled corticosteroids and the prevention of death from asthma. $N$ Engl J Med. 2000;343(5):332-336.

30. Spitzer W, Suissa S, Ernst P, et al. The use of beta-agonists and the risk of death and near death from asthma. $N$ Engl J Med. 1992;326(8) 501-506.

31. Booth S, Wade R, Johnson M, Kite S, Swannick M, Anderson H The use of oxygen in the palliation of breathlessness. A report of the expert working group of the Scientific Committee of the Association of Palliative Medicine. Resp Med. 2004;98(1):66-77.
International Journal of COPD

\section{Publish your work in this journal}

The International Journal of COPD is an international, peer-reviewed journal of therapeutics and pharmacology focusing on concise rapid reporting of clinical studies and reviews in COPD. Special focus is given to the pathophysiological processes underlying the disease, intervention programs, patient focused education, and self management protocols.

\section{Dovepress}

This journal is indexed on PubMed Central, MedLine and CAS. The manuscript management system is completely online and includes a very quick and fair peer-review system, which is all easy to use. Visi http://www.dovepress.com/testimonials.php to read real quotes from published authors. 